\title{
KRT23 Acts as an Oncogene in Hepatocellular Carcinoma by Regulating P21 via PI3K/AKT/GSK3 $\beta$ Pathway
}

\section{Dan Guo}

the first affiliated hosipital of Xi'an Jiaotong University

\section{Wenhui Ma}

the first affiliated hospital of Xi'an Jiaotong University

\section{Ruhua Wang}

the first affiliated hospital of Xi'an Jiaotong University

Yarui Li

the first affiliated hospital of Xi'an Jiaotong University

Abu Taiub mohammed Mohiuddin Chowdhury

the first affiliated hospital of Xi'an Jiaotong University

\section{Mudan Ren}

the first affiliated hospital of Xi'an Jiaotong University

\section{Xinlan Lu}

the first affiliated hospital of Xi'an Jiaotong University

\section{Shuixiang He}

the first affiliated hospital of Xi'an Jiaotong University

Guifang Lu ( $\sim$ Igfluguifang@163.com )

the first affiliated hospital of Xi'an Jiaotong University

\section{Research}

Keywords: keratin23, hepatocellular carcinoma, epithelial - mesenchymal transition, P21, PI3K/AKT/GSK3ßpathway

Posted Date: June 12th, 2020

DOI: https://doi.org/10.21203/rs.3.rs-34680/v1

License: (c) (1) This work is licensed under a Creative Commons Attribution 4.0 International License.

Read Full License 


\section{Abstract}

Background:Hepatocellular carcinoma (HCC) is a leading cancer worldwide for which diagnosis, treatment and progression are largely unknown. Keratin23 is a potential biomarker forHCC development; however, regulatory mechanisms underlying its expression remain unclear. Inthis research we explored the expression and effect of KRT23 underlying HCC development.

Materials and methods:GEPIA was applied to analyze the expression of KRT23 in HCC samples and Kaplan-Merier survival analysis for patients' prognosis. Next, IHC was further conducted for confirming its expression in HCC tissues. Meanwhile qRT-PCR and western blot analysis were applied to examine the expression of KRT23 on both mRNA and protein level in HCC cell lines compared with immortal hepatocyte LO2. Cell experiments including MTT assay, apoptosis analysis, cell cycle assay and clone formation assay were conducted for cell proliferation while transwell assay and scratch test for metastasis in vitro. Moreover, xenograft tumors in nude mice were further conducted for verification in vivo. As for mechanism in depth, immunofluorescence and western blot were operated to explore the effect of KRT23 on EMT and PI3K/AKT/GSK3ßsignaling pathway. Furthermore, Co-immunoprecipitation was applied for interaction between KRT23 and P21. Functional rescue experiments were conducted to further testify their mutual effect.

Results:For this research, we discovered the high expression of KRT23 in HCC samples and cell lines. Functionally, KRT23 knockdown reduced cell proliferation and metastasis in vitro and vivo. Furthermore, KRT23 participated in EMT progression and interacted with P21 to mediate PI3K/AKT/GSK3ßpathway in HCC development.

Conclusion:To summarize, KRT23 accelerated HCC proliferation and metastasis by regulating P21 via $\mathrm{PI3K} / \mathrm{AKT} / \mathrm{GSK} 3 \beta$ pathway.

\section{Background}

Hepatocellular carcinoma (HCC) is still a noteworthy public health issue all over the world even in the coming decade in wake of its fast - rising incidence and high mortality ${ }^{1,2}$. As we all known, HCC development results from gradual accumulation of multiple genetic and factorial regulation, including hepatitis $\mathrm{B}$ and $\mathrm{C}$ viruses, alcohol consumption, aflatoxin exposure, obesity and some with no specific reason ${ }^{3,4}$. Detection and treatments for HCC has been advanced greatly over the past few years, but there is no promising improvement for patients, along with 5 -year survival rate lower than $18 \%$ caused by rather high diagnosis at advanced stage and then limited treatment options ${ }^{5,6}$. Considering the correlation between early detection and prognosis for patients, it's urgent to discover new biomarkers for HCC patients at risk and much more sensitive targets for current therapies.

Expressed in a tissue-specific manner, keratins (KRTs) are accepted as structural proteins that has the intermediate filaments of epithelial cells ${ }^{7}$. Keratin family possesses 50 members, in which KRT9-23 are 
classified to the acidic type while KRT1-8 are basic-neural ${ }^{8}$. Interacted with other proteins or other members in KRT family with various epigenetic modification, keratins take great effect on stress response, several cancers progression and signaling pathways ${ }^{9}$. As a member of acidic keratins, KRT23was firstly discovered in pancreatic cancer cells and was induced by histonehyperacetylation ${ }^{10}$. Meanwhile, the high expression of KRT23 in microsatellite-stable colon cancer (MSS) was applied for distinction MSS from microsatellite-instable colon cancers $(\mathrm{MSI})^{8}$. Moreover, KRT23 as a stress-inducible marker, correlated with the liver disease severity ${ }^{7}$, which predicted that KRT23 might participate in liver disease even cancer. All above reminds us the orientation of KRT23 on HCC development.

For this research, bioinformatic analyses were firstly applied and revealed the high expression of KRT23 in HCC patients and correlation of poor prognosis. Next functional experiments in vitro and xenograft tumors in nude mice were conducted to detect the effect of KRT23 in HCC progression. Furthermore, we found that KRT23 also mediated EMT and interacted with P21 to regulate PI3K/AKT/GSK3ßpathway. Above all, KRT23 may has the potential as a new drug target and diagnostic biomarker for HCC patients.

\section{Materials And Methods}

\section{Bioinformatic analysis}

Gene Expression Profiling Interactive Analysis(GEPIA)was applied for detecting the expression of KRT23 in HCC and normal patients. Then Kaplan-Merier survival analysis was used for the prediction of patients' prognosis. Meanwhile the interaction between KRT23 and otherproteins was explored in STRING: functional protein association networks.

\section{Cell culture and tumor tissues collection}

All cells involved in this research were purchased fromthe Type Culture Collection of the Chinese Academy of Sciences (Shanghai, China). Cells were Cultured with DMEM of high glucose (Hyclone, America), which contained 10\% fetal bovine serum (FBS, Gibico, America) and $100 \mathrm{U} / \mathrm{ml}$ penicillinstreptomycin (Geneview, America). Meanwhile all cells were maintained in sterile and humid cell incubator with $5 \% \mathrm{CO}_{2}$ at $37^{\circ} \mathrm{C}$ and stored at liquid nitrogen. On the other hand, clinical tumor samples and tumor adjacent samples around tumors $5 \mathrm{~cm}$ were collected from pathology department ofFirst Affiliated Hospital of Xi'an Jiaotong Universityafter approved and authorized by the institute of medical ethics.

\section{Cell transfection assay}

Specific interfering RNAs against the sequence of KRT23 or P21 were all designed and synthesized by Genepharma (Shanghai, China) and concrete sequences has been listed in Table 1. Lipofectamine2000 Transfection Reagent (Geneview) was applied as its instruction for importing siRNAs into cells when the cell density attached around $50 \%-70 \%$. In view of transfection efficiency, siKRT23\#1 was selected for further experiment and construction of lentivirus which inserting the sequence of siKRT23\#3 into the 
vector GV248. Lentivirus-KRT23-RNAi was bought from GeneChem (Shanghai, China) and cells transfected with lentivirus were cultured with DMEM/high glucose containing $5 \mu \mathrm{g} / \mathrm{ml}$ puromycin.

\section{RNA isolation and quantitative real-time PCR (qRT-PCR)}

RNA extraction was conducted as the protocol of Trizol Reagent (Invitrogen, USA). The sequences of primers applied for this research had been displayed in Table 2. cDNAs were synthesized as the instruction of EasyQuick RT MasterMix (CWBIO, China) and qRT-PCR was examined using UltraSYBR Mixture ((CWBIO, China). $\beta$-actin was regarded as the control reference when the expression of genes was calculated as the formula $2^{-\Delta \Delta C t}$.

\section{MTT assay}

MTT assay was used to analyze the cell proliferationafter transfection.Cells were seeded into 96-well plates at a density of 5000 cells/well. In the following days, $10 \mu \mathrm{L}$ of $5 \mathrm{mg} / \mathrm{ml}$ MTT was added into every well and after incubating for $4 \mathrm{~h}$ in cell incubator at $37^{\circ} \mathrm{C}$ هdiscardedthe suspension and $150 \mu \mathrm{L}$ DMSO were applied for purple crystal solution at the bottom of 96-well plates. At the end, EnSpire Multimode Plate Reader (PerkinElmer) was used for measuring the optical density (OD) at $490 \mathrm{~nm}$.

\section{Cloning formation assay}

Stable transfected cells were seeded into 6-well plates for 500 cells/well. When one separate cell cloned and formed clusters along with no less than 50 cells after 14 days, the clone formation was fixed by methanol for $15 \mathrm{~min}$ and then colored with $0.1 \%$ crystal violet for $20 \mathrm{~min}$. Images were collected under microscope when the plates were dry.

\section{Flow cytometry}

Cell apoptosis was conducted as the instruction of Annexin V-APC/7-AAD apoptosis kit (MULTI SCIENCES, China). After transfection for $48 \mathrm{~h}$, cells were gathered and washed by PBS for two times. Then $500 \mu \mathrm{L} 1 \times$ Binding buffer was applied to resuspend cells and following $5 \mu \mathrm{L}$ Annexin V-APC and 10 $\mu L$ 7-AAD were added for incubation away from light at room temperature for $5 \mathrm{~min}$. Finally, samples were examined by FALS CALIBAR (USA). As for cell cycle, as the protocol of Cell Cycle Detection Kit (KeyGEN BioTECH, China), $1 \times 10^{6}$ cells were collected and washed by PBS after transfection for $48 \mathrm{~h}$. Then $70 \%$ cold ethyl alcohol was supplied for fixing cells overnight at $4^{\circ} \mathrm{C}$. The next day, PBS was used to wipe off the fixing liquid and then $500 \mu \mathrm{L} \mathrm{PI/RNase} \mathrm{A} \mathrm{solution} \mathrm{prepared} \mathrm{in} \mathrm{advance} \mathrm{at} \mathrm{adequate} \mathrm{ratio} \mathrm{of}$ 9:1 were added and incubated at room temperature for $60 \mathrm{~min}$. identically, samples were detected on FALS CALIBAR (USA).

\section{Transwell assay}

Chambers of $8 \mu \mathrm{m}$ pole size coated with Matrigel (BD Biosciences) were applied for cell invasion. After transfection for $24 \mathrm{~h}$, cells were resuspended using medium with no FBS and seeded on the top of 
chambers which had been put into $600 \mu \mathrm{L}$ medium with $10 \%$ FBS in 24-well plates. Chambers were taken out after placed in cell incubator for $24 \mathrm{~h}$ and washed for 3 times with PBS. Wiped gently with swabs internally, chambers were put into $95 \%$ alcohol for fixation for $15 \mathrm{~min}$ and then stained by $0.1 \%$ crystal violet for $20 \mathrm{~min}$. Images were collected after removing superfluous crystal violet by PBS under the microscope at a magnification of 200x. Considering migration, the protocol was similar with that for invasion, just with no Matrigel for chambers.

\section{Wound healing experiment}

Stable transfected cells were seeded into 6-well plates to attach a confluence of $90 \%-95 \%$ and after stable adhesion, $10 \mu \mathrm{L}$ sterile tips were applied for scratching. In case of interference from cell growth, medium with no FBS was used during the period. Pictures were collected respectively at $0 \mathrm{~h}, 24 \mathrm{~h}$, and $48 \mathrm{~h}$ under the microscope at an amplification of $200 x$.

\section{The oncogenicity in nude mice}

Randomly divided into 2 groups, male athymic 4-week-old nude mice were purchased from the Centre Animal laboratory of Xi'an Jiaotong university and their good care was strictly according to the institution guidelines. Stable- transfected cells were used for xenograft tumors. $200 \mu \mathrm{L}$ stably transfected cells HepG2 containing at least $5 \times 10^{6}$ cells in PBS were injected subcutaneously for detection of cell growth in vivo. Tumor volumes were measured every four days for drawing the growth curve over time. Mice were were narcotized by using ketamine for $100 \mathrm{mg} / \mathrm{kg}$ and sacrificed usingcervical dislocation method. Xenograft tumors were collected after 32 days. As for metastasis, $100 \mu \mathrm{L}$ stably transfected cells HepG2 were injected slowly from tail vein for 2 months and then H\&E staining was conducted to assess pulmonary metastasis. The animal experiment was thoroughly operated according to the Guide for the Care and Use of Laboratory Animals of the National Institutes of Health and was authorized by the medicalethics committee of the First Affiliated Hospital of Xi'an JiaotongUniversity.

\section{H\&E staining and Immunohistochemistry (IHC)}

Xenograft tumors were stored at $10 \%$ formalin overnight and then embedded by paraffin. All conduction was operated as the protocol of Kit of Streptomyces Habilis Ovalbumin -Biotin (ZSGB-BIO, China). Thickness for $4 \mathrm{~mm}$ and put on slides, those tissues was dewaxed using xylene and then hydrated by grade-reduced concentration of alcohol. Then stained with H\&E and observed using microscope. As for IHC, primary antibodies were incubated overnight at $4^{\circ} \mathrm{C}$ afterdewaxing and hydration. The next day secondary antibodies were incubated and then detected using DAB solution. Stained with hematoxylin for cell nucleus, next slides were dehydrated by grade-ascending concentration of alcohol and then transparentized by xylene. Finally sealed by coverslips with neural gum, the slides were observed by microimaging scanning system (Leica). Antibodies applied in detail has been listed in Table 3.

\section{CO-immunoprecipitation (CO-IP) and western blot}


RIPA buffer with proteinase and phosphatase inhibitors was applied for cell protein isolation on ice for 10 min and then primary antibodies or IgG were added for incubation at room temperature for $4 \mathrm{~h}$. Next, activated beads were mixed with protein lysates above and kept shocking at $4^{\circ} \mathrm{Covernight}$. The next day, beads were washed for 3 times using RIPA buffer and resuspended by $1 \times$ loading buffer. Conduction remaining was similar with western blot. Proteins were uploaded into $5 \%$ gel for concentration and then $10 \%$ for dividing during electrophoresis process. Following proteins were transferred onto PVDF membrane with $0.45 \mu \mathrm{m}$ or $0.22 \mu \mathrm{m}$ pole size, which were blocked with $5 \%$ milk without fat and then primary antibodies were incubated respectively at $4{ }^{\circ} \mathrm{C}$ overnight. Secondary antibodies were incubated for $1 \mathrm{~h}$ at room temperature the next day. All bands were observed by FD ${ }^{\mathrm{TM}}$ FDbio- Dura Ecl kit (Fdbio science, China). Application for antibodies in detail was shown in Table 3.

\section{Immunofluorescence}

Sterile slides were put into 6-well plates before Stable transfected cells were seeded into plates. Slides with adherent cells were fixed with $4 \%$ paraformaldehyde for $15 \mathrm{~min}$ and then blocked with goat serum for $30 \mathrm{~min}$. Following primary antibodies were incubated overnight at $4{ }^{\circ} \mathrm{C}$ in a wet black box. The next day, after washed for 3 times by PBS, slides were incubated with secondary antibodies for $1 \mathrm{~h}$ at room temperature. After stained with DAPI for nucleus and covered with anti-fading buffer, images were collected under inverted immunofluorescent microscope (Leica). The details for antibodies showed in Table 3.

\section{Statistical analysis}

The software SPSS 23.0 was applied for statistical analysis. Difference between two paired groups were analyzed by Student's $t$-test and $\chi 2$ testwas applied for analysis of clinical data. $p$ value $<0.05$ was considered as significant difference and $p<0.01$ very significant.

\section{Results}

\section{Overexpression of KRT23 in HCC samples and HCC cell lines}

As is shown in Fig. $1 A$ and $B$, the results of bioinformatic analysis from GEPIA revealed that the expression of KRT23 was higher when compared with that in normal patients $\left({ }^{\star} p<0.01\right)$. Meanwhile, the overexpression of KRT23 indicated poor prognosis that the overall survival for HCC patients with higher expression of KRT23 was shorter than those with lower expression $(p=0.038)$. Next, the results of immunochemistry (IHC) showed that the expression of KRT23 in HCC tumor samples was significantly higher than tumor adjacent tissues (Fig. 1C), accompanied with correlation between the expression of KRT23 and some clinical factors, as shown in Table 4, including tumor size $(p=0.006)$, HBV infection $(p=0.030)$, AFP $(p=0.001)$, pathological grade $(p=0.027)$, TNM stage $(p=0.040)$ and cancer embolus $(p=0.034)$. Then we detected the expression of KRT23 in HCC cell lines. The result of qRT-PCR displayed that KRT23 was overexpressed on mRNA level when compared with that in immortal hepatocyte LO2 (Fig. 1D, $\left.{ }^{*} p<0.05,{ }^{*} p<0.01\right)$, which was familiar with the result of western blot that detecting the expression of 
KRT23 on protein level (Fig. 1E).Moreover, immunofluorescence was applied to acknowledge the location of KRT23 in cytoplasm (Fig. 1F). In view of that, three special interfering RNAs against the sequence of KRT23 was designed and transfected effect was examined by both qRT-PCR and western blot to choose the siKRT23\#1 for the research in depth (Fig. $1 \mathrm{G}$ and $\mathrm{H},{ }^{*} p<0.01$ ). In all, the expression of KRT23 was higher in both HCC patient samples and HCC cell lines. relating to poor prognosis.

\section{KRT23 regulated HCC cell proliferation, including apoptosis and cell cycle}

Clone formation assay and MTT assay were conducted to assess the influence for proliferation. In clony formation assay, the number of clony formation in KRT23 knockdown group was obviously less than that in control and NC group (Fig. 2A, ${ }^{\star} p<0.05,{ }^{*} p<0.01$ ). As for MTT assay, when the expression of KRT23 was knocked down, the HCC cell growth overtimewas retarded when compared with both control and NC group (Fig. $2 \mathrm{~B},{ }^{\star} p<0.05,{ }^{*} p<0.01$ ). Furthermore, flow cytometry suggested that the number of apoptotic cells in KRT23 knockdown group was increased in contrast to control and NC group (Fig. 2D and E, $\left.{ }^{*} p<0.05\right)$. In addition, KRT23 knockdown decreased the cell number in $\mathrm{S}$ phase when compared with that in control and NC group (Fig. $2 \mathrm{~F}$ and $\mathrm{G},{ }^{*} p<0.05$ ). Following the classical biomarkers for apoptosis and cell cycle were detected by western blot (Fig. $2 \mathrm{H}$ and I). Just as the results shown, the expression of PARP/cleaved PARP and Bax were augmented when KRT23 was knocked down while Bcl2 was alleviated; the relative markers for cell cycle involving cyclinD1, cyclinE, CDK4, CDK6, C-MYC were all weakened in siKRT23 group. Above all, KRT23 knockdown inhibited HCC cell proliferation and accelerated apoptosis.

\section{KRT23 mediated HCC cell migration and invasion}

For this part, transwell assay and wound healing assay were used for HCC cell metastasis. In siKRT23 group, the HCC cell number for migration and invasion was apparently decreased compared with that in control and NC group (Fig. $3 A$ and $B, * * p<0.01$ ). similarly, when KRT23 was knocked down, the motility of $\mathrm{HCC}$ cells over time was attenuated (Fig. $3 \mathrm{C}, \mathrm{D}$ and $\mathrm{E},{ }^{*} p<0.05$, ${ }^{\star *} p<0.01$ ). Meanwhile, the expression of MMP9 was detected using western blot and KRT23 knockdown strongly abrogated its expression on protein level (Fig. 3F). To sum up, KRT23 knockdown suppressed the metastasis of HCC cells.

\section{KRT23 controlled HCC proliferation and metastasis in vivo}

The function of KRT23 were further verified in vivo. For assurance, the efficiency for stably transfected cells Hep3B and HepG2 were evaluated using both qRT-PCR and western blot to be available as shown in Fig. $A(\star \star p<0.01) .200 \mu \mathrm{HHepG} 2$ stably transfected with sh-NCor sh-KRT23 in PBS, which contained $5 \times 10^{6}$ cells was subcutaneously injected to assess tumor growth. As the image shown, the tumor volume in shKRT23 group was evidently less than sh-NC group (Fig. 4B), and the growth rate over time was sharply retarded when KRT23 was knocked down ( $* \star p<0.01)$. Considering lung metastasis models, $100 \mu \mathrm{l}$ suspension of HepG2 stably transfected with sh-NC or sh-KRT23 was injected from tail vein. There were much more pulmonary metastatic nodules in sh-NC group when compared with that in sh-KRT23 group (Fig. 4D). Moreover, the expression of Ki67 was detected and as shown in Fig. 4E and F ( $\star \star p<0.01)$, the 
number of Ki67 positive cells was predominantly richer than that in sh-KRT23 group. In a word, KRT23 regulated $\mathrm{HCC}$ growth and pulmonary metastasis in vivo.

\section{KRT23 regulated Epithelial-mesenchymal transition and PI3K/AKT/GSK3 $\beta$ pathway}

As shown in Fig. 5,We inferred that KRT23 may affect EMT progression. No matter the results for immunofluorescence showed or the images in western blotpresented, the expression of E-cadherin, the epithelial relative marker was invigorated when KRT23 was knocked down while the expression of $\mathrm{N}$ cadherin, vimentin, ZEB1 and $\beta$-catenin which all represented the characteristics of mesenchyme, were significantly weakened when in contrast to that in sh-NC or control group (Fig. 5A and B). Furthermore, KRT23 also regulated PI3K/AKT/GSK3 $\beta$ pathway. As is exhibited in Fig. 5C, when KRT23 was knocked down, the expression of PI3K, P-AKT and GSK3 $\beta$ were all decreased on protein level, in spite of no significant difference for AKT.

\section{KRT23 interacted with P21 to mediate HCC cell proliferation and metastasis via PI3K/AKT/GSK3 $\beta$ pathway}

Following we revealed that there was some interaction between KRT23 and P21 (CDKN1A)to mediate HCC progression, which was reminded by the result from STRING (Fig. 6A). Then qRT-PCR and western blot were applied to preliminarily explore their mutual effect. As is shown in Fig. $6 \mathrm{~B}\left({ }^{\star} p<0.05,{ }^{\star} p<0.01\right)$, the expression of P21 was usually elevated when KRT23 was knocked down whether on mRNA or protein level. Subsequently, the interaction between KRT23 and P21 was further confirmed by CO-IP assay (Fig. $6 \mathrm{C})$. Meanwhile, the efficiency of small interfering RNA against the sequence of P21 had been detected to be satisfied (Fig. 6D, ${ }^{\star \star} p<0.01$ ).

Functionally, P21 knockdown accelerated HCC cell growth over time when compared with NC group, which can be rescued when co-transfected siP21 and siKRT23 (Fig. 7A and B, ${ }^{\star} p<0.05,{ }^{*} p<0.01$ ). In clony formation assay, the number of clone formation in P21 knockdown group were more than NC group, but the increase was abolished if KRT23 knockdown was added (Fig. 7C and $D, * p<0.05,{ }^{\star} * p<0.01$ ). As for metastasis, P21 knockdown accelerated HCC cell migration and invasion and the number for migrated and invaded cells was obviously reduced in co-transfected with siP21 and siKRT23 group in contrast to that in siP21 group (Fig. 7Eand F, ${ }^{\star} p<0.05, * \star p<0.01$ ). similarly, the mobility of HCC cells was strengthened when P21 was knocked down. However, KRT23 knockdown distinctly impeded the activation of P21 knockdown on cell moving (Fig. $7 \mathrm{G}$ and $\mathrm{H},{ }^{*} p<0.05$, ${ }^{\star *} p<0.01$ ). In viewof mechanism, the expression of $\mathrm{PI} 3 \mathrm{~K}, \mathrm{P}-\mathrm{AKT}$ and GSK3$\beta$ were all improved in P21 knockdown group, which was reversed by KRT23 knockdown (Fig. 7l).

\section{Discussion}

HCC withdismal prognosis has brought great burdens for public health worldwide although the various prevalence of underlying risk factors in different areas ${ }^{11,12}$. Once discovered, a great deal of HCC patients have missed the best opportunity for surgical resection, following that $70 \%$ patients undertake recurrence 
within 5 years ${ }^{11}$. Furthermore, $\mathrm{HCC}$ is an aggressive solid tumor easily non-sensitive to chemotherapeutics applied at present ${ }^{13}$. Above all, it's imperative to improve the efficacy for identification of novel biomarkers at preliminary stage of $\mathrm{HCC}$ and then make therapies for HCC much more costeffective.Located on chromosome 17q21.2 and with a molecular weight of $48 \mathrm{kDa}$, KRT23 expresses a $1.65 \mathrm{~kb}$ mRNA and has been reported to have some function in several cancers.Protein KRT23 was highly upregulated in primary rectal cancer, which was analyzed by immunochemistry ${ }^{14}$. Meanwhile, KRT23 activated hTERT expression and then accelerated colorectal cancer growth ${ }^{15}$. In prostate basal cell carcinoma, KRT23 was recognized to be overexpressed ${ }^{16}$. As for liver disease, the expression of KRT23 in serum samples was significantly upregulated in $\mathrm{HCC}$, chronic hepatitis compared to normal samples ${ }^{17}$. Moreover, KRT23 was investigated to be a host factor induced by HCV in liver ${ }^{18}$.KimD et al. ${ }^{19}$ detected that KRT23 was one of PPARA targeted, MYC-amplified oncogene in HCC.Taken together, all research above highlighted that KRT23 had the potential to be a diagnostic biomarker for liver cancer ${ }^{19}$. Our research is the first to systematically investigate the effect of KRT23 in HCC development and discover thatKRT23 was overexpressed in HCC tissues and cell lines. Functionally, KRT23 knockdown suppressed $\mathrm{HCC}$ cell proliferation and metastasis in vitro and vivo. Above all, KRT23 might act as an oncogene in HCC.

P21, also known as CDKN1A which resided in 6p21.2 20,21 , has been investigated involvement in cell cycle regulation, differentiation, cell migration, cytoskeletal dynamic, apoptosis, transcription, DNA repair, induction of totipotent stem cells, autophagy and senescence ${ }^{22,23}$. Commonly accepted is that P21 as a member of cyclin-dependent kinase inhibitors (CDKI) interacts with various cell cycle proteins to mediate G1/S growth phase arrest in response to different stimuli ${ }^{24,25}$. P21 was regulated in P53 dependent or independent way at transcriptional level and also controlled by phosphorylation, ubiquitination and localization at post-transcriptional level ${ }^{26}$. Likewise, the function of P21 in cancer progression is rather sophisticated considering cellular environment and its subcellular location ${ }^{27,28}$. In our study, analysis of STRING indicated that KRT23 might interact with P21 and KRT23 knockdown elevated the expressionof P21 whether on mRNA level or protein. Co-immunoprecipitation was conducted to verify the interaction between KRT23 and P21. Furthermore, the promotion for cell proliferation, migration and invasion caused by P21 knockdown was partly reversed by KRT23 knockdown.

Epithelial- mesenchymal transition (EMT) mediated by transcriptional factors is a well-known accelerating process for neoplasia metastasis, along with mesenchymal-like morphology for easier separation from primary sites to distant organs and regulation of related biomarkers, E-cadherin for epithelial reduced while $\mathrm{N}$-cadherin, vimentin and others for mesenchymal elevated ${ }^{29,30}$. Rather multiple researches haveelucidated that there are various signaling cascades participated in EMT, including $\mathrm{PISK} / \mathrm{AKT} / \mathrm{GSK} 3 \beta$ pathway ${ }^{31}$, which is reported to activated in preliminary stage of tumorigenesis and take great effect on cell aerobic glycolysis, tumor cell growth, metastasis, angiogenesis, autophagy and chemoresistance ${ }^{32-34}$. As the downstream of phosphatidylinositol 3-kinase (PI3K), protein kinase B (AKT) is the crucial molecule in response to different stimuli and often activated by phosphorylation at different 
sites, most commonly at Ser $473^{35}$. Then activated AKT inhibits the activity of glycogen synthasekinase 3 Beta (GSK3 $\beta$ ) via its phosphorylation at Ser 9, which generating abundant cellular glycogen for cell survival and subsequent acceleration of important gene transcription in cancer development ${ }^{36,37}$. Our research unraveled that KRT23 knockdown controlled EMT process and restrained the activation of $\mathrm{PISK} / A K T / G S K 3 \beta$ pathway. Moreover, activation of PI3K/AKT/GSK3 $\beta$ pathway caused by P21 knockdown was abrogated by KRT23 knockdown. In all, KRT23 mediated PI3K/AKT/GSK3 $\beta$ pathway via regulating $\mathrm{P} 21$.

\section{Conclusion}

In conclusion, this study revealed that KRT23 was overexpressed in HCC tissues and cell lines and mediated HCC cell growth and metastasis in vitro and vivo. Furthermore, KRT23 participated in EMT and interacted with $\mathrm{P} 21$ via regulating $\mathrm{PI} 3 \mathrm{~K} / \mathrm{AKT} / \mathrm{GSK} 3 \beta$ pathway. Our research gave the orientation for KRT23 as a novel biomarker for HCC detection and even potential target molecule for clinical treatment. However, much more explorations are still needed for successful clinical application in future.

\section{Tables}

Tabla 1. Sequences of siRNAs used in this research.

\begin{tabular}{|c|c|}
\hline siRNAs & sequence \\
\hline siKRT23=1 & 5'-3'GGAUGGCAGUGGAUGACUUTT \\
\hline \multicolumn{2}{|c|}{ 3'-5' AAGUCAUCCACUGCCAUCCTT } \\
\hline siKRT23 $=2$ & 5'-3'GGACACUUGGUAUAAAGAATT \\
\hline \multicolumn{2}{|c|}{ 3'-5' UUCUUUAUACCAAGUGUCCTT } \\
\hline siKRT23 $=3$ & 5'-3' CCAAAGAUCAAGGCCAUAATT \\
\hline \multicolumn{2}{|c|}{ 3'-5'UUAUGGCCUUGAUCUUUGGTT } \\
\hline \multirow[t]{2}{*}{$5 \mathrm{P} 21$} & 5'-3' CCUCUGGCAUUAGAAUUAUTT \\
\hline & 3'-5' AUAAUUCUAAUGCCAGAGGTT \\
\hline \multirow[t]{2}{*}{ nerative control (NC) } & 5'-3'UUCUCCGAACGUGUCACGUTT \\
\hline & 3'-5'ACGUGACACGUUCGGAGAATT \\
\hline
\end{tabular}

Takle 2. Sequences for primers involved.

\begin{tabular}{cl}
\hline primer & \multicolumn{1}{c}{ sequence } \\
\hline KRT23 & forward: AACTAGCACGTGGCTCCCG \\
& reverse: TTTTTTTTTTTTTTTTTGCAGCTAGTGCGGAGTT \\
P21 & forward: TGTCCGTCAGAACCCATGC \\
& reverse:AAAGTCGAAGTTCCATCGTC \\
B-actin & forward:ATCGTGCGTGACATTAAGGAGAAG \\
& reverse:AGGAAGGAAGGCTGGAAGAGTG \\
\hline
\end{tabular}


Takle 3. Concrete information of antibodies applied in this research.

\begin{tabular}{|c|c|c|c|c|c|c|}
\hline \multirow{2}{*}{\multicolumn{2}{|c|}{ Antibedies m specificity }} & \multicolumn{4}{|c|}{ dilution ratio } & \multirow{2}{*}{ company } \\
\hline & & $\mathrm{IHC}$ & IF & WB & IP & \\
\hline \multirow{2}{*}{$\begin{array}{l}\mathrm{KRT} 23 \\
\text { rabbit }\end{array}$} & mouse & $\ldots$ & $1: 50$ & $1: 500$ & $1: 150$ & Santa Cruz \\
\hline & $1: 200$ & & & $\ldots$ & $\ldots$ & proteintech \\
\hline \multicolumn{2}{|c|}{ RARPCleaved Rasp frabbjit } & $\cdots$ & $\cdots$ & $1: 500$ & $\cdots$ & wanleibio \\
\hline Bax & rabbit & $\ldots$ & $\ldots$ & $1: 500$ & $\ldots$ & wanleibio. \\
\hline $\mathrm{Bcl} 2$ & mouse & $\ldots$ & $\ldots$ & $1: 200$ & $\ldots$ & Santa Cruz \\
\hline sxclind1 & rabbit & $\ldots$ & $\ldots$ & $1: 1000$ & $\ldots$ & Abcam. \\
\hline sxclinE1. & rabbit & $\ldots$ & $\ldots$ & $1: 800$ & $\ldots$ & wanleibio \\
\hline CDK4 & rabbit & $\ldots$ & $\ldots$ & $1: 500$ & $\ldots$ & wanleibio \\
\hline CDK6 & rabbit & $\ldots$ & $\ldots$ & $1: 500$ & $\ldots$ & wanleibio \\
\hline s-muge & rabbit & $\ldots$ & $\ldots$ & $1: 500$ & $\ldots$ & proteintech \\
\hline MMP9 & mouse & $\ldots$ & $\ldots$ & $1: 200$ & $\ldots$ & Santa Cruz \\
\hline E-saherin & rabbit & $\ldots$ & $1: 200$ & $1: 1000$ & mans & Cenl Signaling Technology \\
\hline N-sadherin & rabbit & $\ldots$ & $1: 200$ & $1: 1000$ & $0 \quad$ - & Cell Signaling Technology \\
\hline Vimentin & rabbit & $\ldots$ & $1: 200$ & $1 ; 100$ & 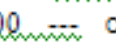 & Cell Slgnaling Technology \\
\hline $\begin{array}{l}\text { ZEB1 } \\
\text { Technology }\end{array}$ & rabbit & $\ldots$ & . & - & $1: 1000$ & Cell Slgnaling \\
\hline B-catenin & rabbit & $\ldots$ & $\ldots$ & $1: 1000$ & $\ldots$ & Cell Signaling Technology \\
\hline P21 & rabbit & - & $\ldots$ & $1 ; 1000$ & $1: 100$ & Cell Signaling Technology \\
\hline GAPDH & mouse & $\ldots$ & $\ldots$ & $1: 5000$ & $\ldots$ & CWBIO \\
\hline \multicolumn{2}{|c|}{ 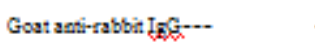 } & $\ldots$ & $\ldots$ & $1: 10000$ & $\ldots$ & TDY Biotech \\
\hline \multicolumn{2}{|c|}{ Gout acti-moses If } & $\ldots$ & $\ldots$ & $1: 10000$ & $\ldots$ & TDY Biotech \\
\hline \multicolumn{2}{|c|}{ Gout acti-rabbit IgG, } & $\ldots$ & $1: 200$ & $\ldots$ & $\ldots$ & ZhuangZhibie \\
\hline
\end{tabular}

Table 4. The expression of KRT23 in HCC patient samples related to clinical factors.

\begin{tabular}{|c|c|c|c|c|}
\hline \multirow[t]{2}{*}{ Characteristics } & \multirow[t]{2}{*}{ total } & \multicolumn{2}{|c|}{$\mathrm{KRT} 23$} & \multirow[t]{2}{*}{$p$ value } \\
\hline & & high & low & \\
\hline \multicolumn{5}{|l|}{ Age } \\
\hline$<59$ & 35 & 27 & 8 & 0.650 \\
\hline$\geq 59$ & 25 & 18 & 7 & \\
\hline \multicolumn{5}{|l|}{ Gender } \\
\hline Male & 49 & 31 & 18 & 0.454 \\
\hline Female & 11 & 5 & 6 & \\
\hline \multicolumn{5}{|l|}{ Tumor size } \\
\hline$<5 \mathrm{~cm}$ & 26 & 16 & 10 & $0.006^{\circ}$ \\
\hline$\geq 5 \mathrm{~cm}$ & 34 & 31 & 3 & \\
\hline \multicolumn{5}{|l|}{ HBV infection } \\
\hline Positive & 48 & 43 & 5 & $0.030^{\circ}$ \\
\hline Negative & 12 & 7 & 5 & \\
\hline \multicolumn{5}{|l|}{$\mathrm{AFP}(\mathrm{ng} / \mathrm{ml})$} \\
\hline$<400$ & 34 & 16 & 18 & $0.001^{\circ}$ \\
\hline 2400 & 26 & 23 & 3 & \\
\hline \multicolumn{5}{|l|}{ Pathological grade } \\
\hline Well and moderate & 48 & 23 & 25 & $0.027^{*}$ \\
\hline Low & 12 & 10 & 2 & \\
\hline \multicolumn{5}{|l|}{ TNM stage } \\
\hline $\mathrm{Ta}, \mathrm{T}_{1}$ and $\mathrm{T}_{2}$ & 31 & 21 & 10 & $0.040^{\circ}$ \\
\hline $\mathrm{T}_{2}$ and $\mathrm{T}_{4}$ & 29 & 26 & 3 & \\
\hline \multicolumn{5}{|l|}{ Cancer embolus } \\
\hline Positive & 21 & 18 & 3 & $0.034^{\circ}$ \\
\hline nerative & 39 & 23 & 16 & \\
\hline
\end{tabular}

*The $p$ value in bold and italic means significant difference. 


\section{List Of Abbreviations}

HCC:Hepatocellular carcinoma

KRTs:keratins

MSS:microsatellite-stable colon cancer

MSI:microsatellite-instable colon cancers

GEPIA:Gene Expression Profiling Interactive Analysis

siRNAs:Specific interfering RNAs

qRT-PCR: quantitative real-time PCR

OD:optical density

IHC: Immunohistochemistry

CO-IP: CO-immunoprecipitation

CDKI:cyclin-dependent kinase inhibitors

EMT:Epithelial- mesenchymal transition

PI3K:phosphatidylinositol 3-kinase

AKT:protein kinase B

GSK3ß:glycogen synthasekinase 3 Beta

\section{Declarations}

\section{Ethics approval and consent to participate}

The study was conducted in accordance with the National Institutes of Health "Guide for the Care and Use of Laboratory Animal" and approved by the medical ethics committee of Xi'an Jiao Tong University.

\section{Consent for publication}

All authors involved have read this manuscript and approve to submit to your journal for publication.

\section{Availability of data and materials}

The whole data and materials supporting the conclusions were included in this manuscript. 


\section{Conflicts of interest}

The authors declare that they have no conflict of interest.

\section{Funding}

This work was supported by the National Natural Science Foundation of China (No. 81502095) and the Social Development, Scientific and Technological Research Project of Shaanxi Province(No. 2015SF055).

\section{Author contributions}

D G and $Y L$ conceivedanddesigned the experiments, $W M$ assisted in collection of information for clinical patients and $\mathrm{G} L$ contacted pathological department for IHC. R W and Mohiuddin help perform the experiments and analyze the data. $M R$ and $X L$ secured research funding supports. $S H$ help revised this manuscript prepared and written by D G.

\section{Acknowledgements}

None.

\section{References}

1. Siegel RL, Miller KD, Jemal A. Cancer statistics, 2020. CA Cancer J Clin. Jan 2020;70(1):7-30.

2. Dasgupta P, Henshaw C, Youlden DR, Clark PJ, Aitken JF, Baade PD. Global Trends in Incidence Rates of Primary Adult Liver Cancers: A Systematic Review and Meta-Analysis. Front Oncol. 2020;10:171.

3. Marquardt JU, Edlich F. Predisposition to Apoptosis in Hepatocellular Carcinoma: From Mechanistic Insights to Therapeutic Strategies. Front Oncol. 2019;9:1421.

4. Dimri M, Satyanarayana A. Molecular Signaling Pathways and Therapeutic Targets in Hepatocellular Carcinoma. Cancers (Basel). Feb 20 2020;12(2).

5. Miller KD, Nogueira L, Mariotto AB, et al. Cancer treatment and survivorship statistics, 2019. $C A$ Cancer J Clin. Sep 2019;69(5):363-385.

6. Rebouissou S, Nault JC. Advances in molecular classification and precision oncology in hepatocellular carcinoma. J Hepatol. Feb 2020;72(2):215-229.

7. Guldiken N, Kobazi Ensari G, Lahiri P, et al. Keratin 23 is a stress-inducible marker of mouse and human ductular reaction in liver disease. J Hepatol. Sep 2016;65(3):552-559.

8. Birkenkamp-Demtroder K, Mansilla F, Sorensen FB, et al. Phosphoprotein Keratin 23 accumulates in MSS but not MSI colon cancers in vivo and impacts viability and proliferation in vitro. Mol Oncol. Sep 2007;1(2):181-195.

9. Liffers ST, Maghnouj A, Munding JB, et al. Keratin 23, a novel DPC4/Smad4 target gene which binds 14-3-3epsilon. BMC Cancer. Apr 14 2011;11:137. 
10. Jin-San Zhang LW, Haojie Huang, Matthew Nelson, and David I. Smith. Keratin 23 (K23), a Novel Acidic Keratin, Is Highly Induced by Histone Deacetylase Inhibitors During Differentiation of Pancreatic Cancer Cells. GENES, CHROMOSOMES \& CANCER. 2001;30:123-135.

11. Fujiwara N, Liu PH, Athuluri-Divakar SK, Zhu S, Hoshida Y. Risk Factors of Hepatocellular Carcinoma for Precision Personalized Care. In: Hoshida Y, ed. Hepatocellular Carcinoma: Translational Precision Medicine Approaches. Cham (CH)2019:3-25.

12. Singal AG, Lampertico P, Nahon P. Epidemiology and surveillance for hepatocellular carcinoma: New trends. J Hepatol. Feb 2020;72(2):250-261.

13. Vitale A, Trevisani F, Farinati F, Cillo U. Treatment of hepatocellular carcinoma in the Precision Medicine era: from treatment stage migration to therapeutic hierarchy. Hepatology. Feb 162020.

14. Flebbe H, Hamdan FH, Kari V, et al. Epigenome Mapping Identifies Tumor-Specific Gene Expression in Primary Rectal Cancer. Cancers (Basel). Aug 9 2019;11(8).

15. Zhang N, Zhang R, Zou K, et al. Keratin 23 promotes telomerase reverse transcriptase expression and human colorectal cancer growth. Cell Death Dis. Jul 27 2017;8(7):e2961.

16. Su X, Long Q, Bo J, et al. Mutational and transcriptomic landscapes of a rare human prostate basal cell carcinoma. Prostate. May 2020;80(6):508-517.

17. Wang K, Xu X, Nie Y, Dai L, Wang P, Zhang J. Identification of tumor-associated antigens by using SEREX in hepatocellular carcinoma. Cancer Lett. Aug 28 2009;281(2):144-150.

18. Gao X, Yang J. Identification of Genes Related to Clinicopathological Characteristics and Prognosis of Patients with Colorectal Cancer. DNA Cell Biol. Apr 2020;39(4):690-699.

19. Kim D, Brocker CN, Takahashi S, et al. Keratin 23 Is a Peroxisome Proliferator-Activated Receptor Alpha-Dependent, MYC-Amplified Oncogene That Promotes Hepatocyte Proliferation. Hepatology. Jul 2019;70(1):154-167.

20. Ohashi R, Angori S, Batavia AA, et al. Loss of CDKN1A mRNA and Protein Expression Are Independent Predictors of Poor Outcome in Chromophobe Renal Cell Carcinoma Patients. Cancers (Basel). Feb 17 2020;12(2).

21. Sun $X, H u Y, W u ~ J$, et al. RBMS2 inhibits the proliferation by stabilizing P21 mRNA in breast cancer. $J$ Exp Clin Cancer Res. Dec 4 2018;37(1):298.

22. Kreis NN, Louwen F, Yuan J. The Multifaceted p21 (Cip1/Waf1/CDKN1A) in Cell Differentiation, Migration and Cancer Therapy. Cancers (Basel). Aug 21 2019;11(9).

23. Xu S, Feng Z, Zhang M, et al. hSSB1 binds and protects p21 from ubiquitin-mediated degradation and positively correlates with p21 in human hepatocellular carcinomas. Oncogene. May 12 2011;30(19):2219-2229.

24. Manu KA, Cao PHA, Chai TF, Casey PJ, Wang M. p21cip1/waf1 Coordinate Autophagy, Proliferation and Apoptosis in Response to Metabolic Stress. Cancers (Basel). Aug 3 2019;11(8).

25. Ehedego H, Boekschoten MV, Hu W, et al. p21 ablation in liver enhances DNA damage, cholestasis, and carcinogenesis. Cancer Res. Mar 15 2015;75(6):1144-1155. 
26. Kreis NN, Friemel A, Ritter A, et al. Function of p21 (Cip1/Waf1/CDKN1A) in Migration and Invasion of Cancer and Trophoblastic Cells. Cancers (Basel). Jul 15 2019;11(7).

27. Calvisi DF, Donninger H, Vos MD, et al. NORE1A tumor suppressor candidate modulates p21CIP1 via p53. Cancer Res. Jun 1 2009;69(11):4629-4637.

28. Hou Z, Guo K, Sun X, et al. TRIB2 functions as novel oncogene in colorectal cancer by blocking cellular senescence through AP4/p21 signaling. Mol Cancer. Dec 12 2018;17(1):172.

29. Liu J, Wang C, Ma X, et al. High expression of CCR5 in melanoma enhances epithelial-mesenchymal transition and metastasis via TGFbeta1. J Pathol. Apr 2019;247(4):481-493.

30. Jiang H, Zhou Z, Jin S, et al. PRMT9 promotes hepatocellular carcinoma invasion and metastasis via activating PI3K/Akt/GSK-3beta/Snail signaling. Cancer Sci. May 2018;109(5):1414-1427.

31. Zhao GX, Xu YY, Weng SQ, et al. CAPS1 promotes colorectal cancer metastasis via Snail mediated epithelial mesenchymal transformation. Oncogene. Jun 2019;38(23):4574-4589.

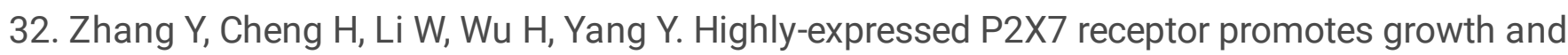
metastasis of human HOS/MNNG osteosarcoma cells via PI3K/Akt/GSK3beta/beta-catenin and mTOR/HIF1alpha/VEGF signaling. Int J Cancer. Aug 15 2019;145(4):1068-1082.

33. Ajimu Keremu1 XM, Abudusaimi Aimaiti2, Maimaiaili Yushan1, Yamuhanmode Alike1, Yilizati Yilihamu1, Aihemaitijiang Yusufu1. NRSN2 promotes osteosarcoma cell proliferation and growth through PI3K/Akt/MTOR and Wnt/B-catenin signaling. Am J Cancer Res. 2017;7(3):565-573.

34. Tang W, Lv B, Yang B, et al. TREM2 acts as a tumor suppressor in hepatocellular carcinoma by targeting the PI3K/Akt/beta-catenin pathway. Oncogenesis. Jan 25 2019;8(2):9.

35. Chen H, Wong CC, Liu D, et al. APLN promotes hepatocellular carcinoma through activating PI3K/Akt pathway and is a druggable target. Theranostics. 2019;9(18):5246-5260.

36. Zhao SJ, Kong FQ, Jie J, et al. Macrophage MSR1 promotes BMSC osteogenic differentiation and M2-like polarization by activating PI3K/AKT/GSK3beta/beta-catenin pathway. Theranostics. 2020;10(1):17-35.

37. Wu J, Ru NY, Zhang Y, et al. HAb18G/CD147 promotes epithelial-mesenchymal transition through TGF-beta signaling and is transcriptionally regulated by Slug. Oncogene. Oct 27 2011;30(43):44104427.

\section{Figures}



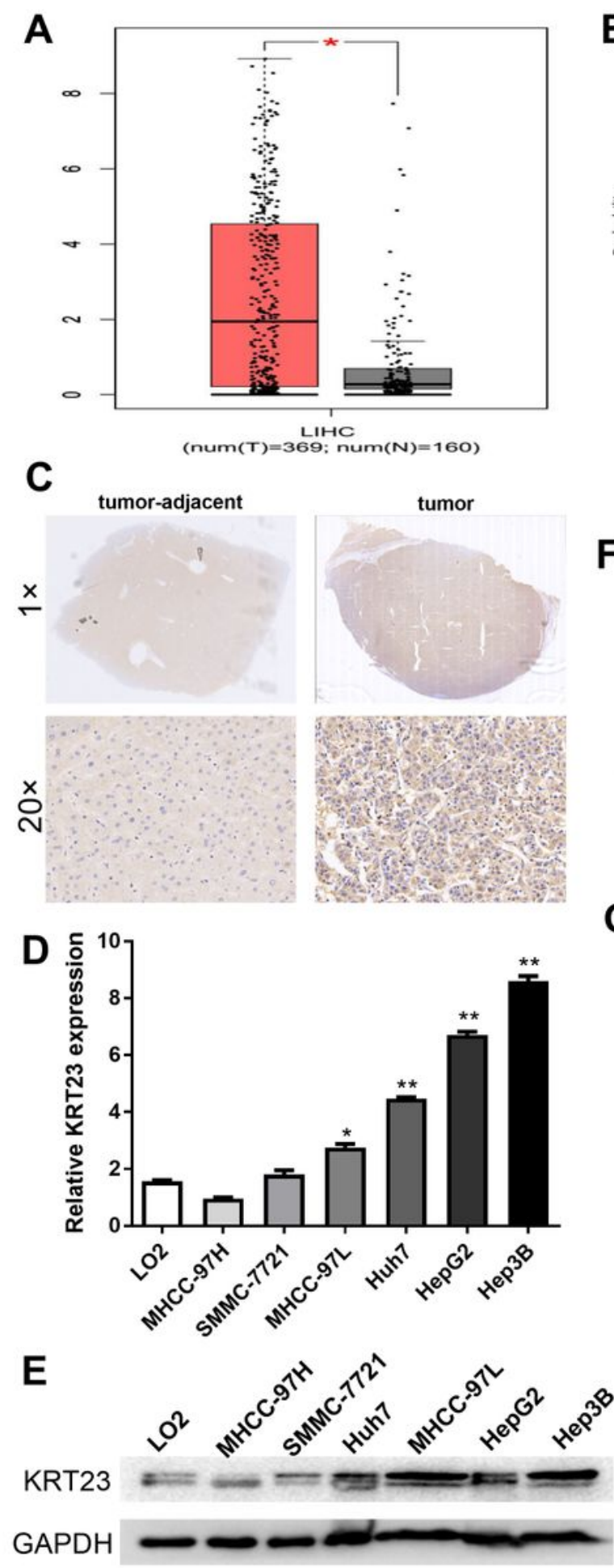
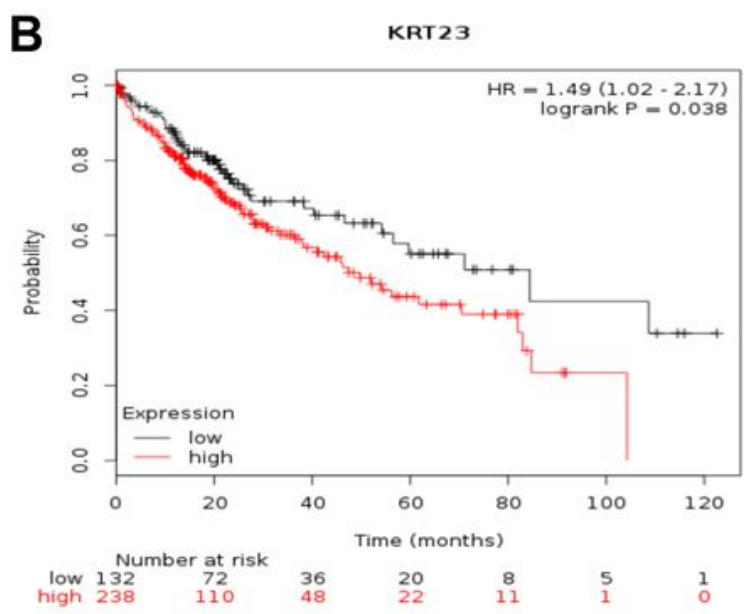

$\mathbf{F}$

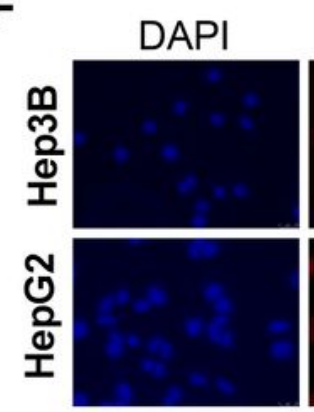

G

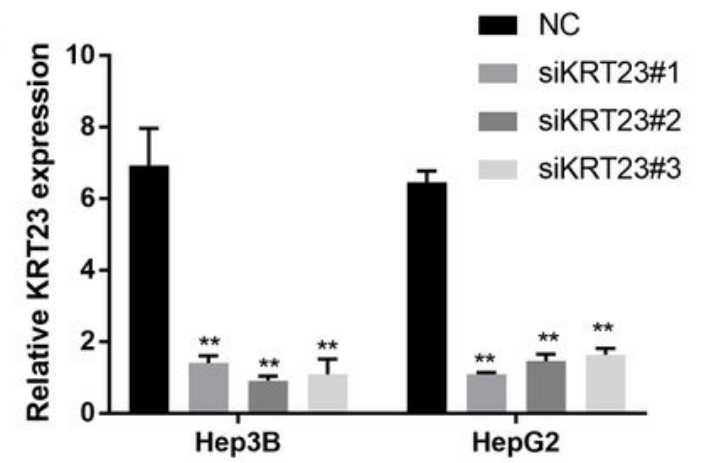

H

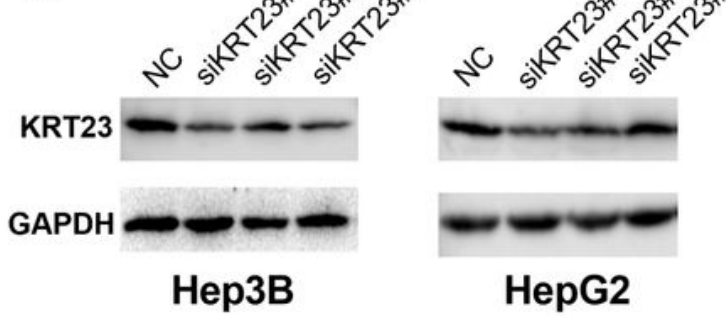

\section{Figure 1}

The overexpression of KRT23 was indicated in HCC samples and HCC cell lines. A. The analysis of GEPIA showed the higher expression of KRT23 in HCC samples when compared with normal patients. ${ }^{*} \mathrm{p}<0.01$. B. Patients with higher expression of KRT23 displayed rather poor prognosis. $p=0.038$.C. IHC results indicated the higher expression of KRT23 in HCC patient samples than tumor adjacent tissues.D-E. Compared with immortal hepatocyte LO2, the expression of KRT23 on both mRNA and protein level in 
HCC cell lines involving MHCC-97L, Huh7, HepG2 and Hep3B was obviously higher. ${ }^{\star} p<0.05,{ }^{\star \star} p<0.01$. F. Immunofluorescence was applied to show location of KRT23 in cytoplasm. G. The result of qRT-PCR showed the efficiency of siRNAs targeting the sequence of KRT23 (siKRT23). ${ }^{*} p<0.01$. H. Western blot was conducted to further verify the efficiency of siKRT23 on protein level.
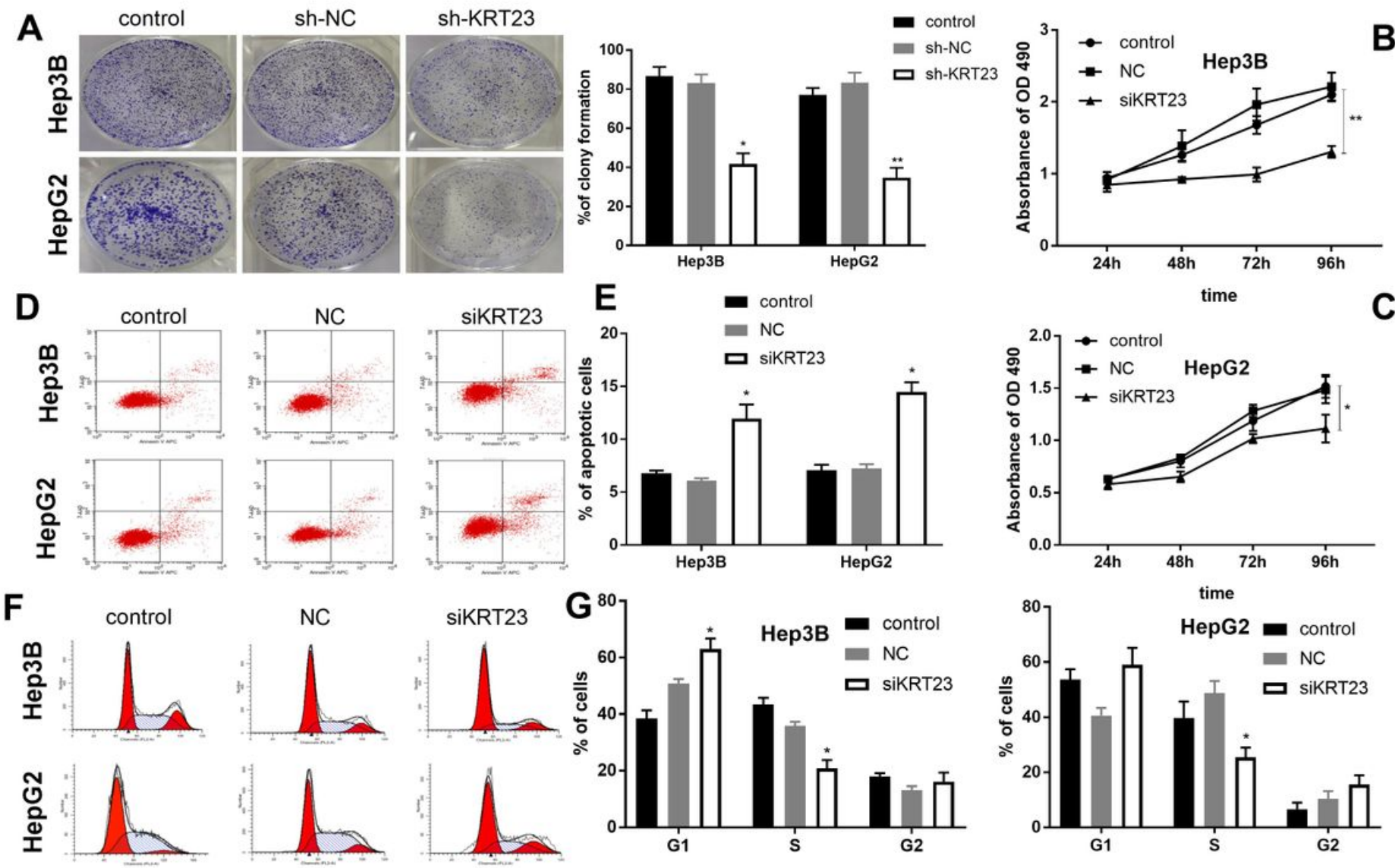

control NC siKRT23 control NC siKRT23

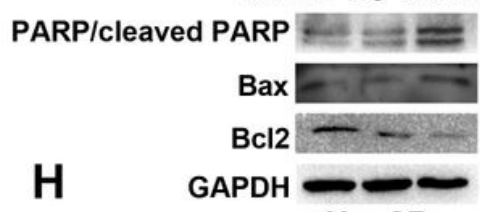

Hep3B

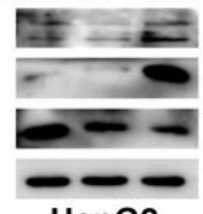

HepG2 control NC siKRT23

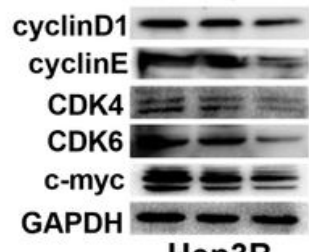

Hep3B

B control NC siKRT23

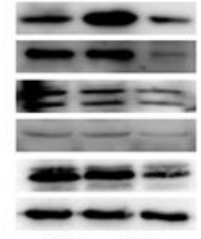

HepG2

Figure 2

KRT23 regulated HCC cell growth including apoptosis and cell cycle. A. When KRT23 was knocked down, the number of clone formation was decreased compared with control or sh-NC group. ${ }^{*} p<0.05$, $\star \star p<0.01$.B-C. Cell growth over time in KRT23 knockdown group was inhibited in contrast to control or NC group. ${ }^{*} p<0.05,{ }^{*} p<0.01$.D-E. The number of apoptotic cells in KRT23 knockdown group was significantly more than control or NC group. ${ }^{*} p<0.05$. F-G. The percentage of cells in $S$ phase was obvious less than control or NC group. ${ }^{*} p<0.05$. H-I. several classical biomarkers during apoptosis and cell cycle was detected after KRT23 was knocked down. 
A Hep3B

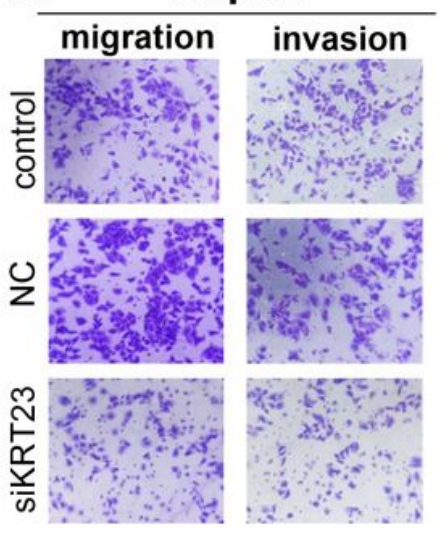

B

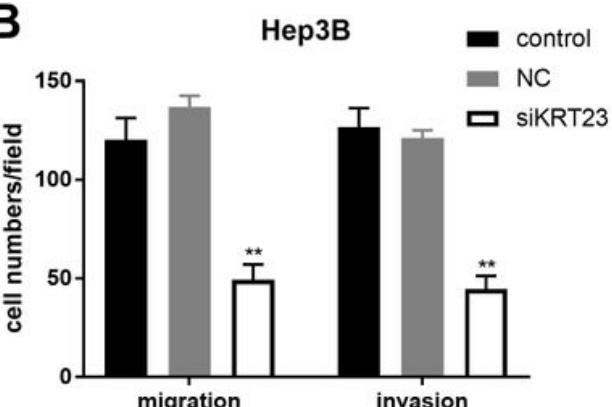

$\mathbf{F}$

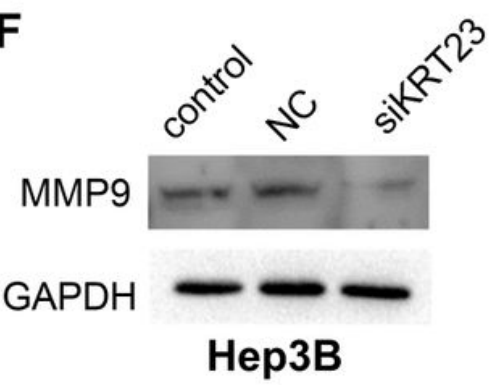

HepG2
Hep3B

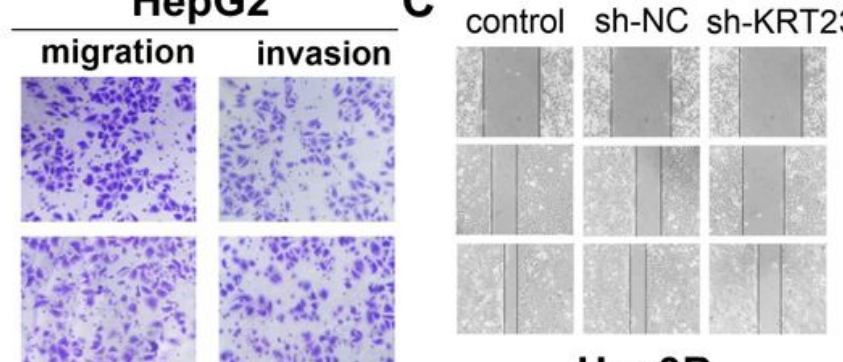

control sh-NC sh-KRT23

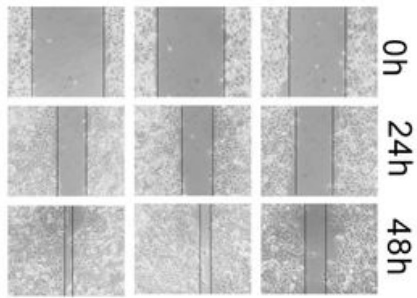

HepG2
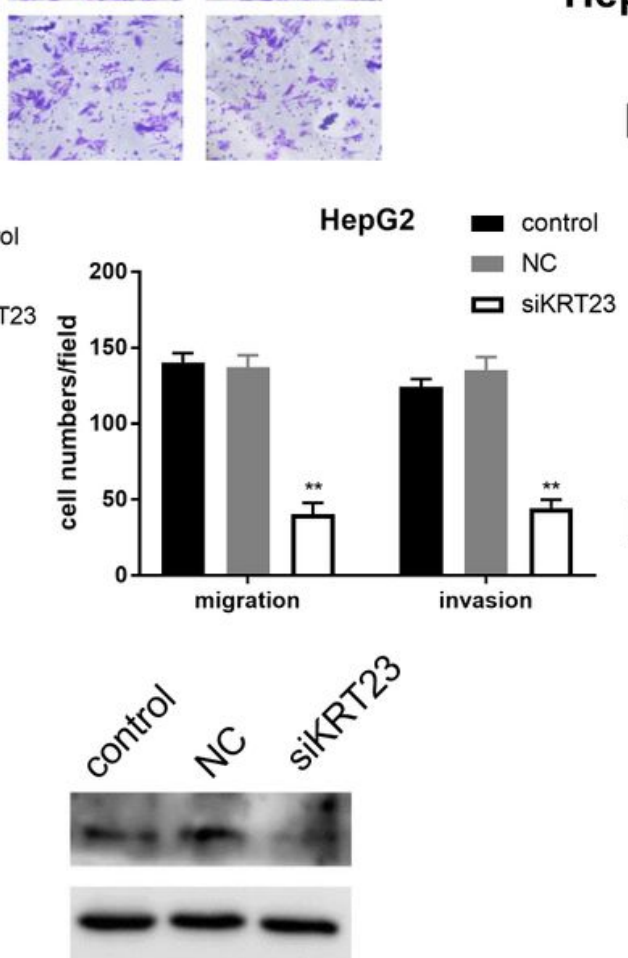

HepG2
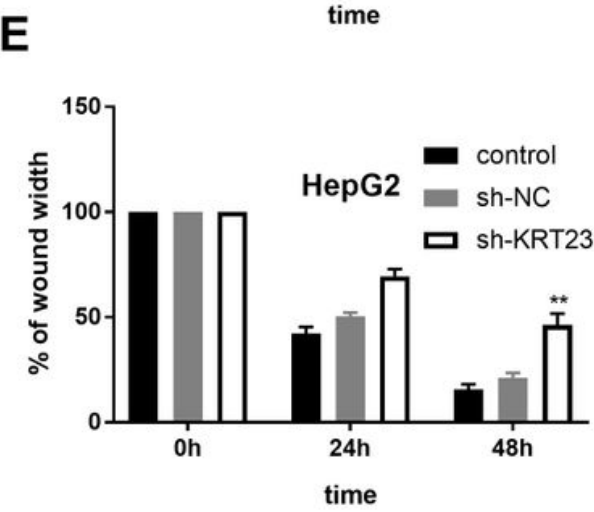

Figure 3

KRT23 mediated HCC cell migration and invasion. A-B. KRT23 knockdown alleviated migration and invasion of HCC cells when compared with control or NC group. ${ }^{*} p<0.01$.C-E. The motility of cells was repressed when KRT23 was knocked down. ${ }^{\star} p<0.05,{ }^{\star \star} p<0.01$.F. The expression of MMP9 on protein level was evidently reduced in KRT23 knockdown group. 

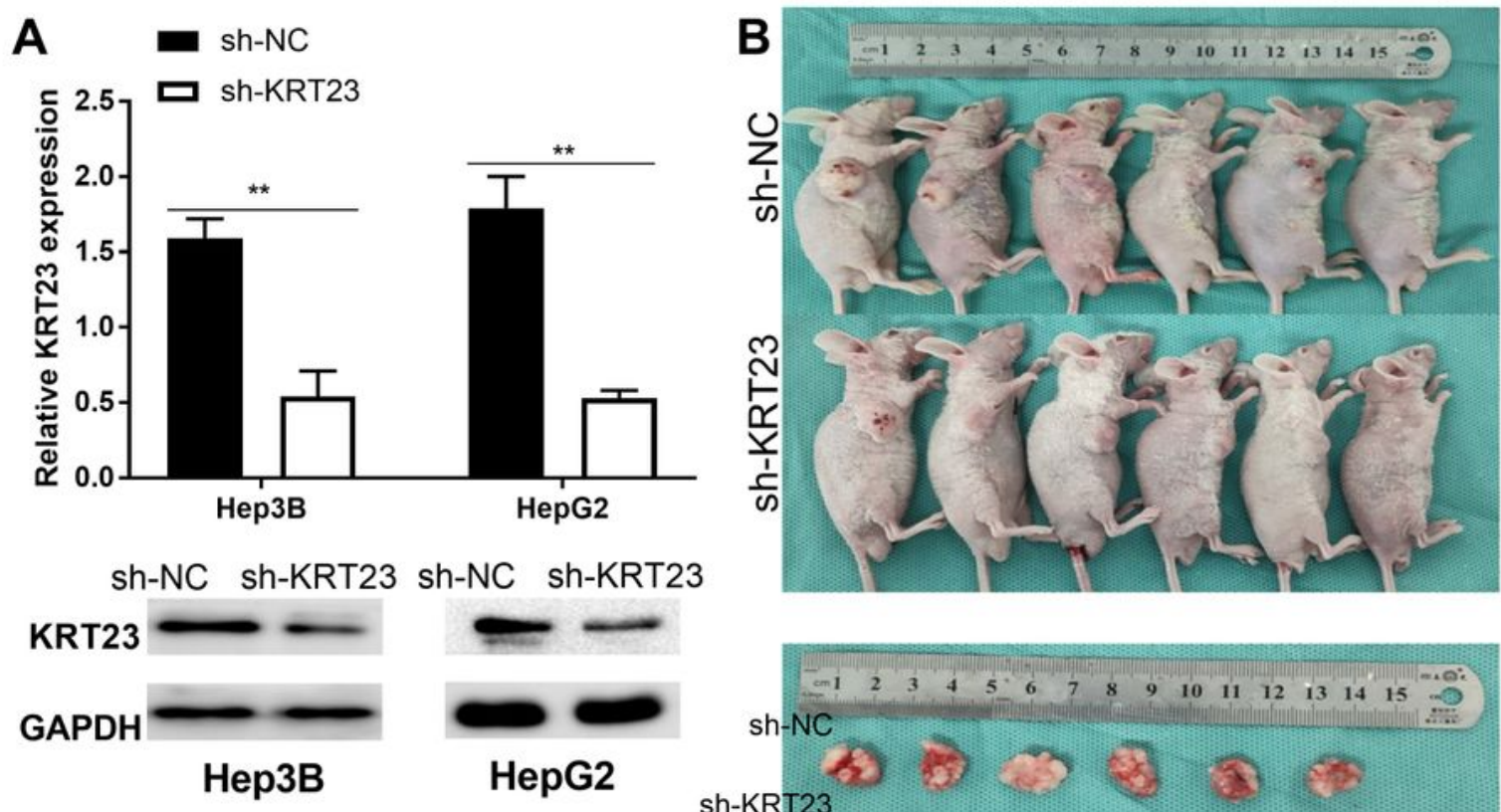

C
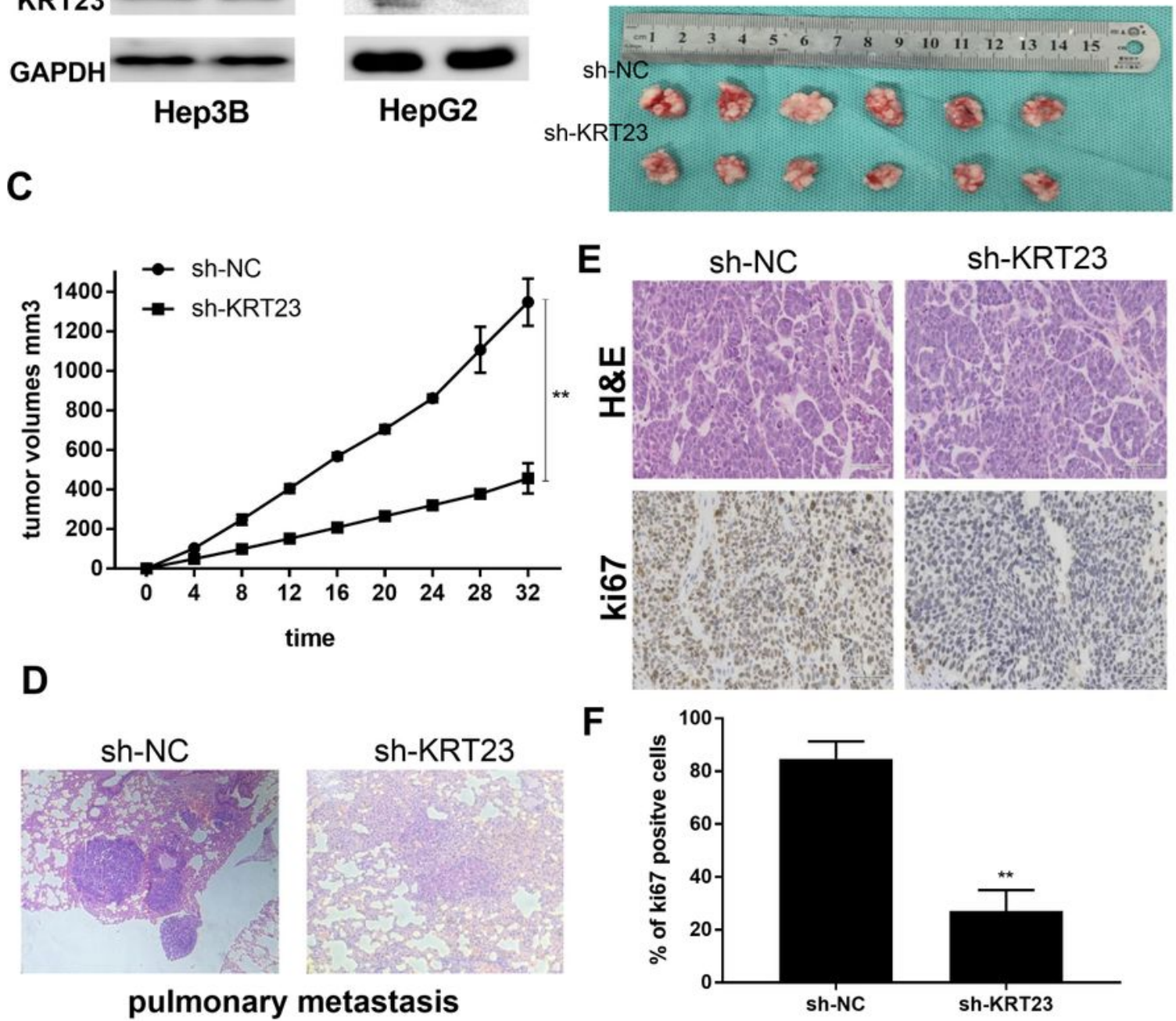

Figure 4

KRT23 controlled HCC proliferation and metastasis in vivo. A. qRT-PCR and western blot were applied for detecting the efficiency of stable transfection using virus in Hep3B and HepG2. ${ }^{\star \star} p<0.01$. B.The classical images for xenograft tumor models in nude mice. C. Tumor volumes over time were detected for around one month and KRT23 knockdown retarded the tumor growth in vivo. ${ }^{* \star} \mathrm{p}<0.01$. D. The representative 
pictures of H\&Estaining for pulmonary metastasis. E-F. Images of H\&Estaining for xenograft tumors and when KRT23 was knocked down, the number of ki67 positive cells were clearly reduced. ${ }^{*} p<0.01$.

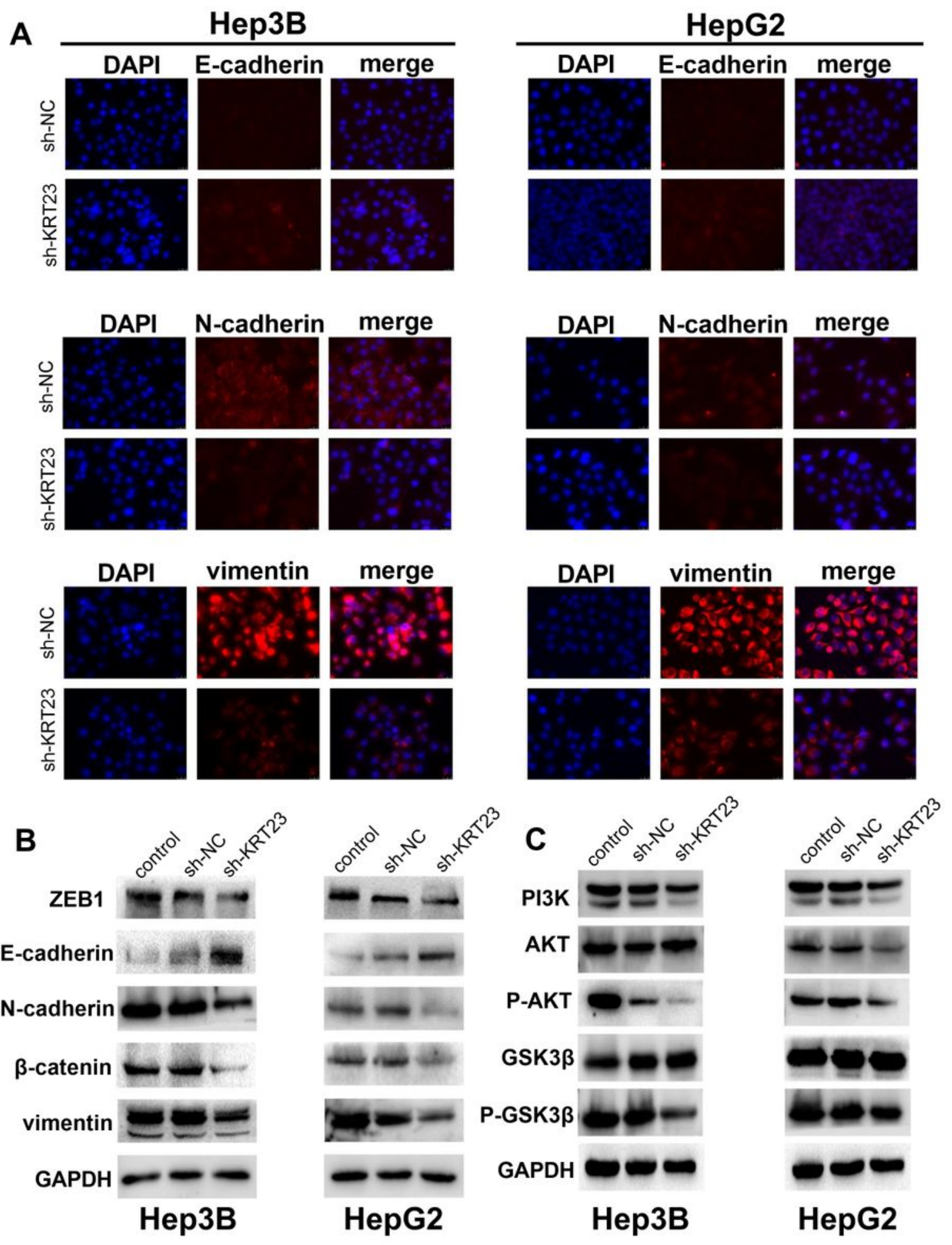

Figure 5

KRT23 regulated Epithelial-mesenchymal transition and PI3K/AKT/GSK3 $\beta$ pathway. A. The results of immunofluorescence revealed that the expression of epithelial marker E-cadherin was increased while mesenchymal relative biomarkers $\mathrm{N}$-cadherin and vimentin were decreased when KRT23 was knocked 
down. B. The western blot showed that on protein level KRT23 knockdown suppressed the expression of mesenchymal markers, including ZEB1, N-cadherin, $\beta$-catenin and vimentin while epithelial marker $\mathrm{E}$ cadherin was elevated.C.The expression of PI3K, P-AKT and p-GSK3 $\beta$ were all alleviated when KRT23 was knocked down. However, there was no significant difference for the expression of AKT and GSK3 $\beta$.

A

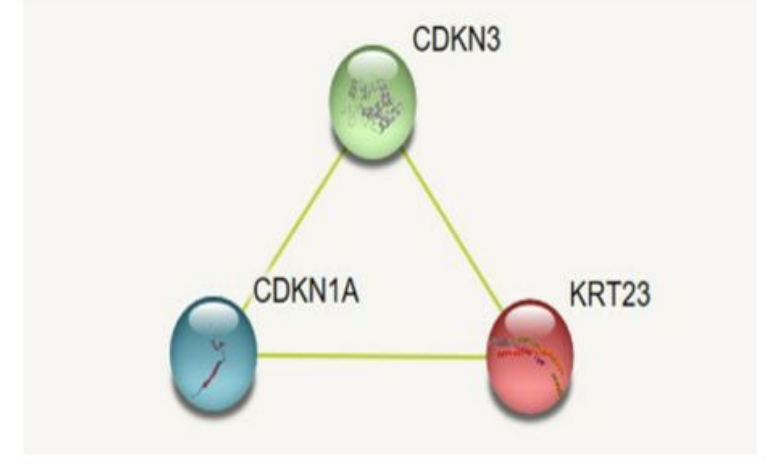

B

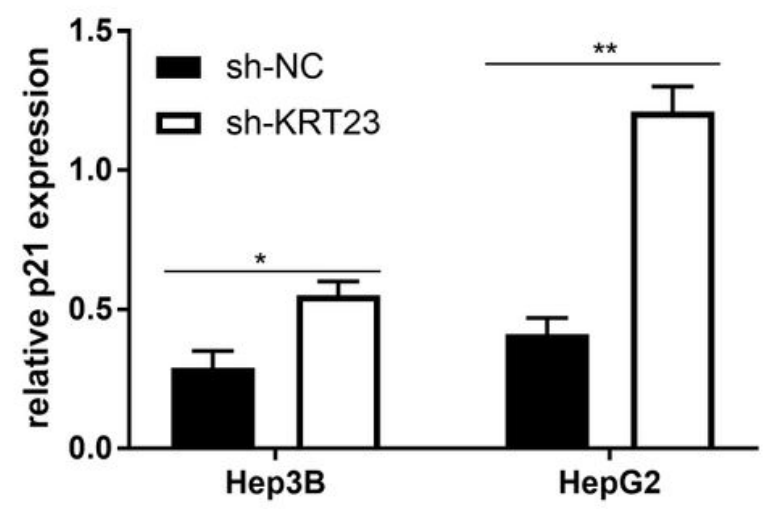

Hep3B

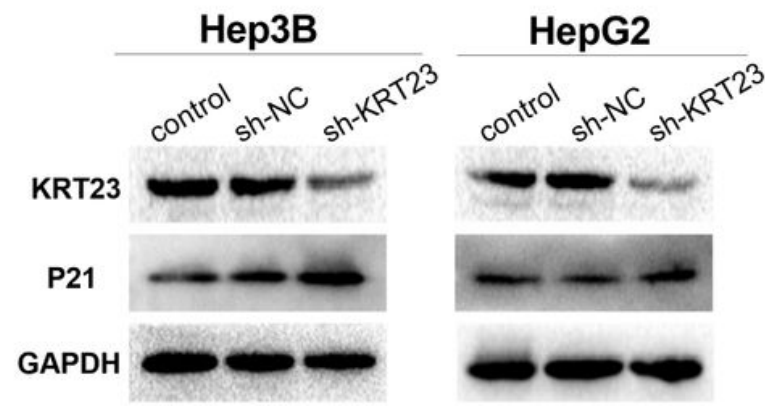

C
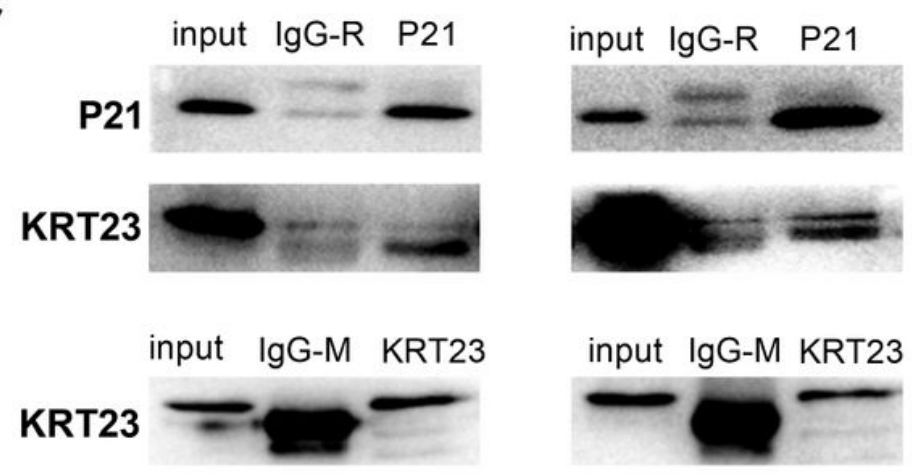

P21

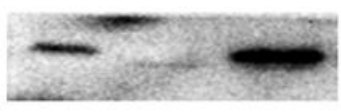

Hep3B

D

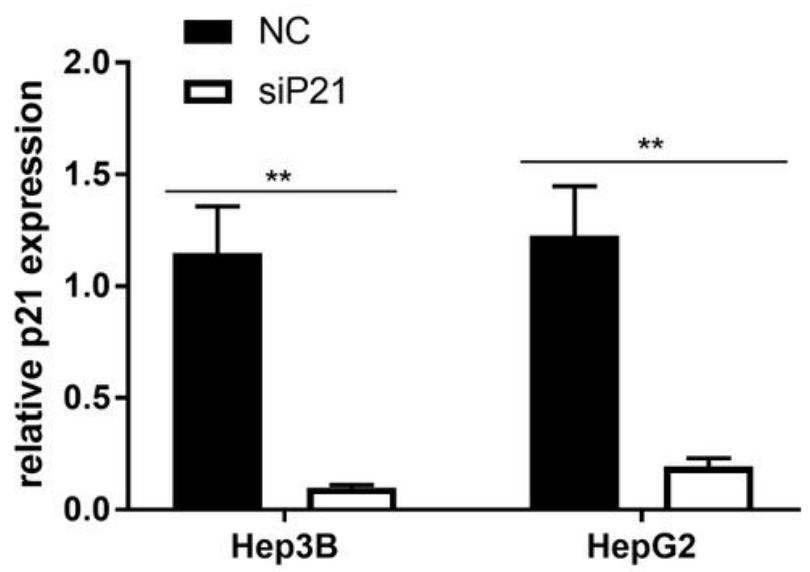

Figure 6

KRT23 interacted with P21. A. The result from STRING reminded that KRT23 might interact with P21 (CDKN1A).B.The expression of P21 whether on mRNA or protein level was both improved when KRT23 was knocked down. ${ }^{*} p<0.05,{ }^{*} p<0.01$. C.The result of immunoprecipitation confirmed the interaction between KRT23 and P21. D. The efficiency of siP21 was verified by qRT-PCR to be available. ${ }^{\star \star} p<0.01$. 


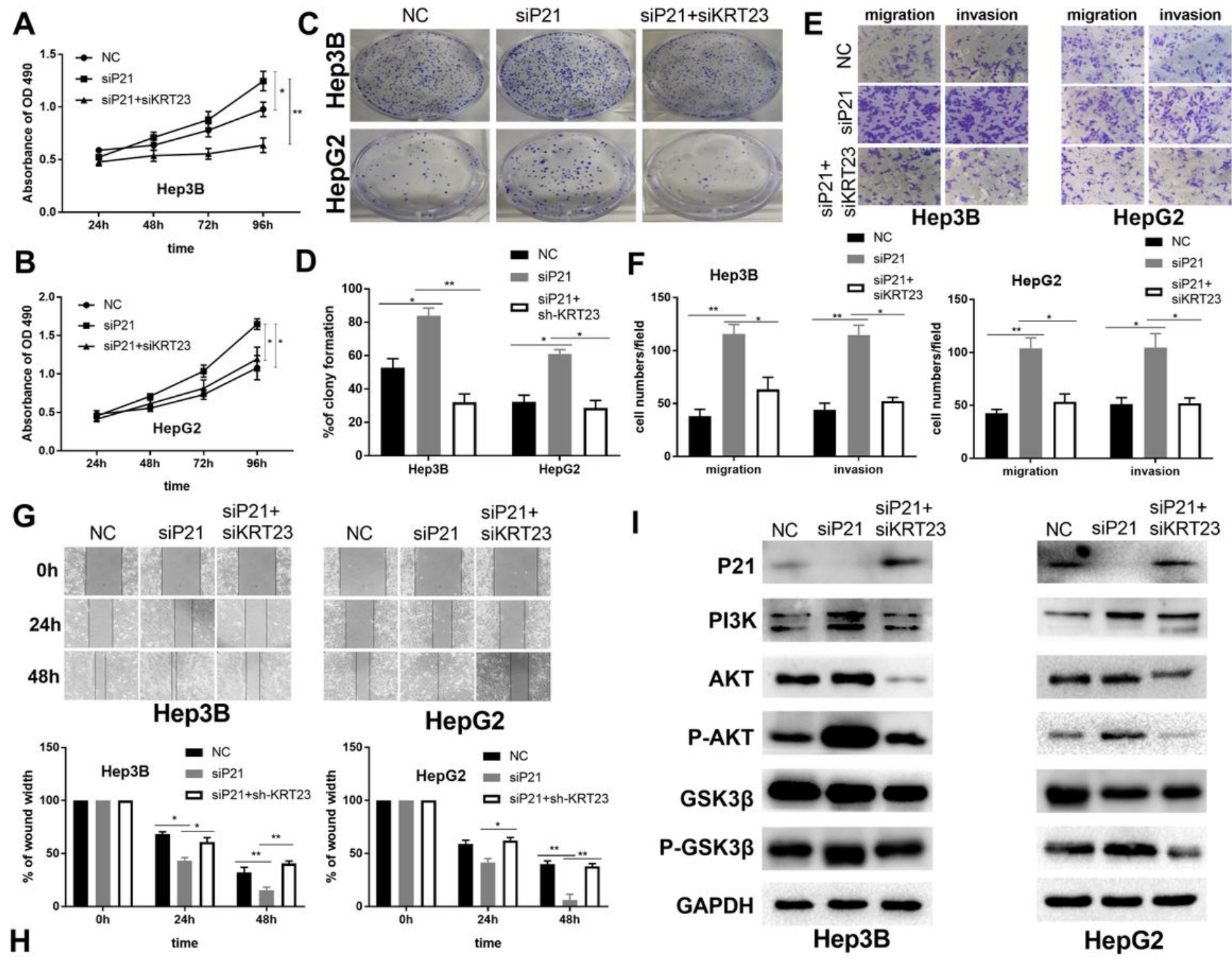

Figure 7

KRT23 interacted with P21 to mediate HCC cell proliferation and metastasis via PI3K/AKT/GSK3ßpathway. A-B. P21 knockdown accelerated the cell growth overtime but when cotransfected with siKRT23, the increase was abolished. ${ }^{*} p<0.05$, ${ }^{* *} p<0.01$.C-D. The number of clone formation was evidently increased in siP21 group when compared with NC group, which was reversed by KRT23 knockdown. ${ }^{\star} p<0.05$, ${ }^{\star *} p<0.01$.E-F. P21 knockdown promoted cell migration and invasion while in co-transfected with siP21 and siKRT23 group, the migrated and invaded cells were reduced rapidly. ${ }^{*} p<0.05,{ }^{*} \mathrm{p}<0.01$.G-H. After P21 was knocked down, the cell motility was reinforced, which was partly abrogated when co-transfected with siKRT23. ${ }^{*}<<0.05$, ${ }^{*} p<0.01 . I . P 21$ knockdown strengthened the expression of PI3K, P-AKT and P-GSK3 $\beta$ but in co-transfected with siP21 and siKRT23 group, the elevation was weakened to some extent. Similarly, the expression of AKT and GSK3 $\beta$ had no obvious change. 

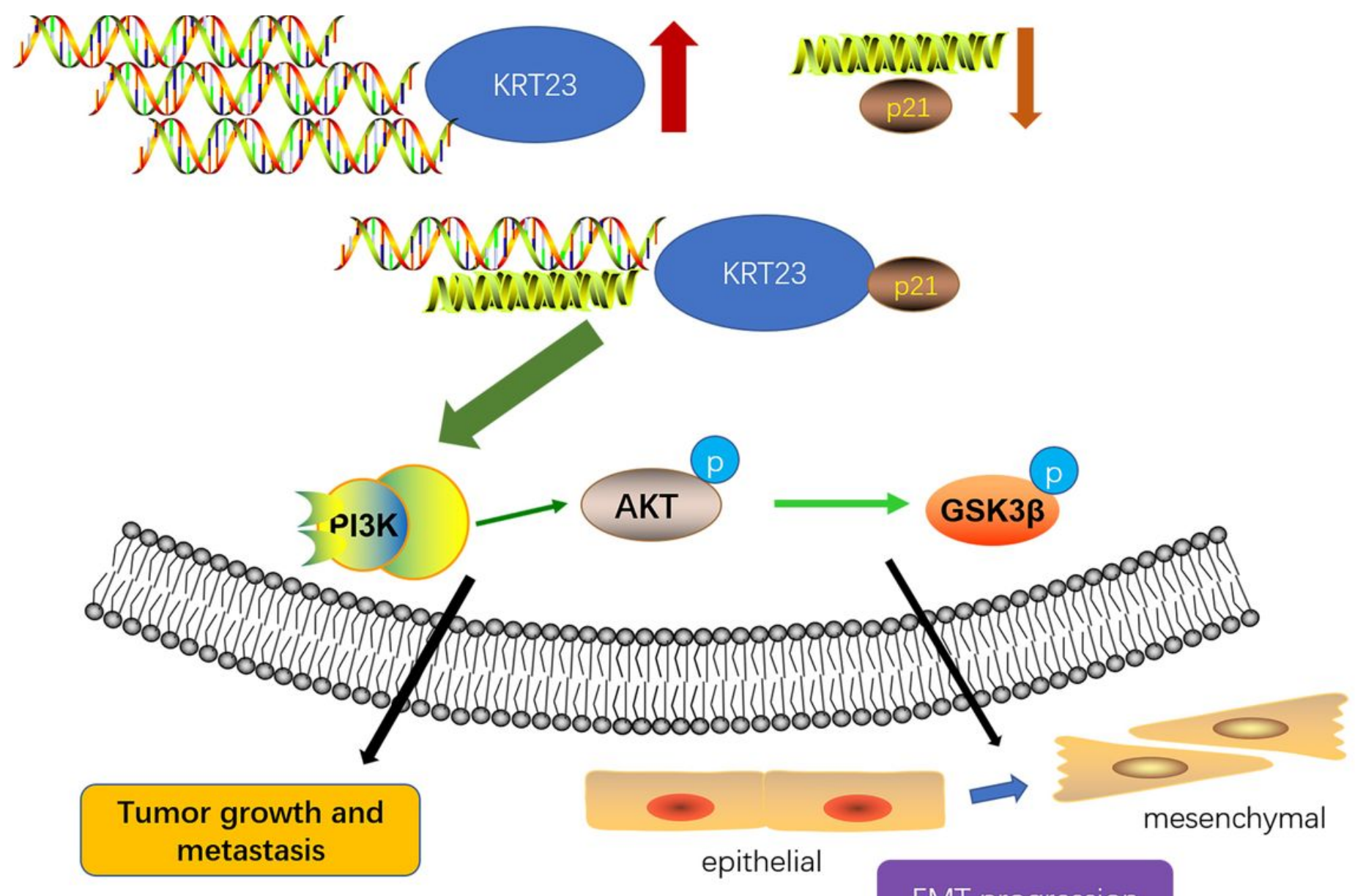

EMT progression

Figure 8

Schematic diagram for the function of KRT23 on HCC development for this research. 